\title{
Consensus on Pegylated Interferon Alpha in Treatment of Chronic Hepatitis B
}

\author{
Wenhong Zhang ${ }^{\# 1}$, Dazhi Zhang ${ }^{\# 2}$, Xiaoguang Dou $^{3}$, Qing Xie ${ }^{4}$, Jiaji Jiang ${ }^{5}$, Xinyue Chen ${ }^{6}$ \\ and Hong Ren*2
} ${ }^{1}$ Huashang Hospital of Fudan University, Shanghai, China; ${ }^{2}$ The Second Affiliated Hospital of Chongqing Medical University,
Chongqing, China; ${ }^{3}$ Shengjing Hospital of China Medical University, Shenyang, China; ${ }^{4}$ Rui Jin Hospital Affiliated to Shanghai Jiao
Tong University School of Medicine, Shanghai, China; ${ }^{5}$ First Affiliated Hospital, Fujian Medical University, Fuzhou, China; ${ }^{6}$ You An
Hospital, Capital Medical University, Beijing, China

Citation of this article: Zhang W, Zhang D, Dou X, Xie Q, Jiang J, Chen $\mathrm{X}$, et al. Consensus on pegylated interferon alpha in treatment of chronic hepatitis B. J Clin Transl Hepatol 2018;6(1):1-10. doi: 10.14218/JCTH.2017.00073.

\section{Introduction}

As advice and consensus on the pegylated-interferon (PegIFN) treatment for chronic hepatitis $\mathrm{B}(\mathrm{CHB})$ in China, the Expert Advice on Peg-IFN Treatment for CHB was published in the Chinese Journal of Infectious Diseases in 2007, and updated in 2010 and 2012.1,2 Previous versions of the Expert Advice described optimized patients for Peg-IFN treatment (baseline guided therapy; BGT), basic principles of treatment adjustment according to the response to the therapy (response guidance therapy; RGT), dosage adjustment based on adverse effects and symptomatic treatment towards adverse reactions. As a supplement to clinical guidelines of CHB management, Expert Advice has deepened clinicians' awareness of individualized Peg-IFN treatment for CHB patients, playing a positive role in guiding the rational use of interferon.

Seeing as the last update of Expert Advice, following the revised version of China's CHB Prevention and Treatment Guidelines and international guidelines for the treatment of $\mathrm{CHB}$ and expanded clinical research, new evidence from evidence-based medicine and a new concept of Peg-IFN in the treatment of CHB has motivated us to review the previous version of Expert Advice. In 2017, the expert group, under the premise of conforming with the principle of Expert Advice, refined and supplemented some of the suggestions and explored hot issues related to the current Peg-IFN treatment,

Keywords: Hepatitis B; Chronic; Interferons; Therapy; Consensus. Abbreviations: ALT, alanine aminotransferase; $A S T$, aspartate aminotransferase; BGT, baseline guided therapy; $C H B$, chronic hepatitis $B$; $H B e A g$, hepatitis e antigen; $\mathrm{HBsAg}$, hepatitis B surface antigen; HBV, hepatitis B virus; $\mathrm{HCC}$, hepatocellular carcinoma; NA, nucleos(t)tide analogue; NPV, negative predictive value; Peg-IFN, pegylated-interferon; PPV, positive predictive value; RGT, response guidance therapy; SVR, sustained viral response; TSH, thyrotropic hormone; ULN, upper limit normal.

Received: 8 November 2017; Revised: 5 February 2018; Accepted: 9 February 2018

${ }^{\#}$ Wenhong Zhang and Dazhi Zhang contributed equally to the article.

* Correspondence to: Hong Ren, The Second Affiliated Hospital of Chongqing Medical University, Chongqing 400010, China. E-mail: renhong0531@vip.sina.com forming a new version of Expert Consensus on Peg-IFNa in the Treatment of $\mathrm{CHB}$ to further standardize the clinical use and improve the efficacy of Peg-IFN therapy to achieve treatment goals.

\section{Treatment goals of $\mathrm{CHB}$}

$\mathrm{CHB}$ treatment goal is to delay the progress of $\mathrm{CHB}$, reduce the incidence of cirrhosis and hepatocellular carcinoma (HCC), and improve the patient survival rate. Guidelines of 2015 American Association for the Study of Liver Diseases, ${ }^{3} 2015$ Asian Pacific Association for the Study of the Liver, ${ }^{4} 2015$ Chinese Society of Hepatology 5 and 2017 European Association for the Study of the Liver ${ }^{6}$ emphasized that the ideology for $\mathrm{CHB}$ treatment is persistent clearance of hepatitis B surface antigen ( $\mathrm{HBsAg})$, with or without seroconversion. In China's new version of CHB Guidelines, it is the first time the term 'clinical cure' has been used and it means sustained undetectable hepatitis $B$ virus (HBV) DNA, alanine aminotransferase (ALT) normalization, HBsAg clearance and resolution of residual liver injury. The serum HBsAg quantitative level and the intrahepatic covalent closed circular DNA are positively correlated, which is an alternative indicator of infected liver cells. ${ }^{7}$ According to a long-term follow-up study in Taiwan performed by Tseng et al. ${ }^{8}$ and a meta-analysis conducted by Liu et al., ${ }^{9}$ the disease development risk lessens with low level of $\mathrm{HBsAg}$, and the risk of HCC occurrence is drastically diminished with HBsAg clearance. These studies suggest that the quantitative level of HBsAg is an independent predictor of the progress of $\mathrm{CHB}$, and a low level of HBsAg suggests a good prognosis of the patient.

Suggestion 1: For $\mathrm{CHB}$ patients with antiviral therapy indications, if appropriate, i.e. the patient's baseline HBsAg level is lower or (and) HBsAg level shows a good response during treatment, the ideal therapy should be pursued as far as possible in order to achieve clinical cure (clearance of HBsAg and/or seroconversion).

\section{Seizing the CHB treatment opportunity}

The immune active phase (immune clearance phase) is the best period for antiviral therapy ${ }^{3-6}$ in patients with $\mathrm{CHB}$. The immune active phase is characterized by persistent increase or fluctuation of ALT, virus replication, active liver inflammation or fibrosis of liver tissue. It is difficult to understand the timing of interferon therapy on the patient's ALT level. ALT 
level changes are relatively intuitive indicators of immune response in patients with $\mathrm{CHB}$. The immune active phase initiates with fluctuations of ALT levels, namely "increase, decrease and normalization" with different immune reactive states. Patients with higher ALT levels have stronger immune response, while those with lower ALT levels have weaker immune response. The sustained response rate is higher in patients after antiviral treatment with higher ALT levels, such as those with 2 times upper limit normal (ULN), or even more than 5 times ULN, lower levels of serum HBV DNA, such as below $1 \times 10^{6}$ copies $/ \mathrm{mL}$, and hepatocellular inflammatory necrosis. ${ }^{1}$ In addition, about $5 \%$ to $15 \%$ of patients in the inactive phase may have one or several episodes of hepatitis (i.e. the immune re-active phase), manifesting negative hepatitis e antigen (HBeAg), anti-HBe positivity, HBV DNA at medium to high levels of replication ( $>20000 \mathrm{IU} / \mathrm{mL}$ ) and persistent or repeated abnormalities of ALT, which turns to HBeAg-negative chronic hepatitis. ${ }^{5}$ The immune reactive period is also an ideal time for antiviral therapy. ${ }^{3}$

Suggestion 2: Regardless of positive or negative $\mathrm{HBeAg}$, CHB patients can take Peg-IFN antiviral therapy, as long as they are in the immune active and reactive phases, and have no Peg-IFN contraindications.

\section{Principle of individualized treatment}

Dosage and duration of the therapy are clearly stated by China's and international guidelines or consensus on Peg-IFN therapy of CHB. The recommended dosage of Peg-IFN $\alpha-2 a$ with $\mathrm{HBeAg}$-positive or $\mathrm{HBeAg}$-negative $\mathrm{CHB}$ is $180 \mu \mathrm{g}$ via subcutaneous injection once weekly for 48 weeks. ${ }^{2}$ Theoretically, it is not recommended to extend the treatment without any consideration. The basic dosage and duration of therapy are proposed on the design and results of clinical trials. This is because basic situation, drug response and tolerance between clinically-treated patients and patients admitted to clinical trials are different.

In order to improve the patient's compliance and treatment efficacy during clinical practice, it is necessary and rational to adjust the dosage and duration, or even to stop the treatment, according to individual patient's treatment responses and tolerance. Mainly based on the patient's tolerance, individual treatment adjustment involves adjusting the dosage of Peg-IFN, extending the time interval of the injection, suspending Peg-IFN treatment and reinforcing follow-up observations. Once adverse reactions are reduced or subside, the usual dosage should be resumed or medication should be resumed from low dosage. ${ }^{2}$ In the meantime, the stop rule in the principle of individualized treatment plays an important role in clinical practice.

Response-guided treatment adjustment (the RGT rule) should be conducted at week 24, rather than week 48 . $^{2}$ Therefore, it is important to predict the effect of long-term therapy within the shortest finite time possible. In recent years, the long-term efficacy prediction research has made great progress, providing much useful evidence for clinical reference. Predictive indicators involved in the efficacy prediction of $\mathrm{CHB}$ are mainly changes in HBV DNA levels, quantitative or semi-quantitative changes in $\mathrm{HBeAg}$, and especially the quantitative changes of HBsAg in the early stage of the treatment.

The important evidence after stopping Peg-IFN treatment for the prediction of persistent response is HBsAg quantification. Numerous domestic and foreign scholars, such as
Sonneveld, Piratvisuth, Liaw, Yang, Marcellin, et al., have accurately studied the instructive significance of early stage HBsAg quantification for dosage adjustment of Peg-IFN, ${ }^{10-13}$ which is discussed in details with specific suggestions in "Individualized Application Strategy of Peg-IFN on naïve and nucleos(t)tide analogue (NA)-treated patients" of the "Expert Consensus".

Suggestion 3: For individualized treatment regimens, treatment adjustment of dosage, duration of treatment and even drug withdrawal should be done according to the patient's tolerance and response to treatment. HBV DNA, $\mathrm{HBeAg}$ and $\mathrm{HBsAg}$ quantification should be performed regularly, before and during the therapy, with HBsAg playing a particularly important role in guiding adjustment of the therapeutic regimen.

\section{Individualized treatment strategy for naïve CHB patients}

\section{Drug efficacy evaluation before treatment}

Most extensive clinical studies have confirmed the efficacy of Peg-IFN treatment on CHB. Asian-based studies conducted by Lau et al. ${ }^{14,15}$ showed that the HBeAg seroconversion rate of $271 \mathrm{HBeAg}$-positive patients who received Peg-IFN $\alpha-2 \mathrm{a}$ treatment for 48 weeks was $42 \%$ at 48 weeks after the end of the treatment. Neptuane study and its long-term follow-up study mainly based on Asian patients showed that the $\mathrm{HBeAg}$ seroconversion rate of $\mathrm{HBeAg}$-positive $\mathrm{CHB}$ patients who received Peg-IFN $\alpha$-2a therapy for 48 weeks were as high as $36.2 \%{ }^{11}$ and $48 \%{ }^{16}$ at 24 weeks and 5 years after the end of treatment, respectively. Studies conducted by Marcellin et $a .^{13}$ showed that the sustained response rate in $\mathrm{HBeAg-}$ negative $\mathrm{CHB}$ patients who received Peg-IFN $\alpha-2$ a treatment for 48 weeks increased continuously after the end of treatment. Patients with HBV DNA $\leq 2000 \mathrm{IU} / \mathrm{mL}$ accounted for $31 \%$ at 1 year after the end of treatment, $88 \%$ of which maintained the response for 5 years after the end of treatment. The HBsAg clearance rate was $5 \%$ at 1 year after the end of treatment, and increased to $12 \%$ at 5 years after completing therapy. Studies conducted by Stelma et al. ${ }^{17}$ found that the 5 years' cumulative HBsAg clearance rates of HBeAg-positive and $\mathrm{HBeAg}$-negative patients who received combined therapy of Peg-IFN $\alpha-2 a$ and adefovir dipivoxil for 48 weeks are $19.3 \%$ and $17.2 \%$, respectively, $88 \%$ of which showed anti-HBs antibody (>10 IU/L).

These studies suggest that Peg-IFN-based monotherapy or combined therapy can achieve sustained response in CHB patients after completing therapy. The European Association for the Study of the Liver Guidelines of CHB treatment in 2012 highlighted that the best option for $\mathrm{HBeAg}$-positive patients to achieve $\mathrm{HBeAg}$ seroconversion and $\mathrm{HBeAg}$-negative patients to achieve a sustained response after completion of a finite course of treatment is to accept Peg-IFN therapy. ${ }^{18}$ Patient baseline characteristics contribute to selecting patients for interferon treatment. Two early stage global randomized and controlled trials of $\mathrm{HBeAg}$-positive $\mathrm{CHB}$ patients with $B / C$ genotype showed that patients with low baseline HBV DNA ( $<20000 \mathrm{IU} / \mathrm{mL}$ ) and high ALT levels ( $\geq 2 \times$ ULN) were able to obtain higher sustained response with Peg-IFN $\alpha-2 a$ treatment. ${ }^{19}$ Neptuane study showed that HBeAg seroconversion rates of $\mathrm{HBeAg}$-positive $\mathrm{CHB}$ patients with baseline ALT more than 2 to 5 times ULN and ALT more than 5 to 10 times ULN who received Peg-IFN $\alpha$-2a therapy for 48 weeks were 
$44.8 \%$ and $61.1 \%$ at 24 weeks after the end of treatment, respectively. For patients with baseline ALT $<2 \times U L N$, the HBeAg seroconversion rate was only $18.5 \% .^{11}$

Two recent studies have found that low baseline $\mathrm{HBsAg}$ levels can predict treatment response after completing therapy. A retrospective meta-analysis on $\mathrm{HBeAg}$-positive $\mathrm{CHB}$ patients with $\mathrm{B} / \mathrm{C}$ genotype $(n=647)$ from three randomized and controlled Peg-IFN $\alpha-2 a$ studies found that patients with baseline $\mathrm{HBsAg} \leq 25000 \mathrm{IU} / \mathrm{mL}$ achieved higher $\mathrm{HBeAg}$ clearance rate $(35 \%$ vs. $16.3 \%, p<0.0001)$ at 24 weeks after the end of treatment. ${ }^{20}$ Another real-world study analyzing $201 \mathrm{CHB}$ patients with Peg-IFN treatment found that baseline $\mathrm{HBsAg}<25000 \mathrm{IU} / \mathrm{mL}$ was an independent predictor of $\mathrm{HBeAg}$ seroconversion at 1 year after the end of treatment for HBeAg-positive patients (OR $=10.45, p=0.025) .{ }^{21}$

Suggestion 4: The principle of patient selection for better clinical efficacy with Peg-IFN treatment (i.e. baseline-guided therapy) involves level of ALT in rise and fall, HBV DNA level $<2 \times 10^{6-8} \mathrm{IU} / \mathrm{mL}$ or fluctuation, and quantitative HBsAg at a relatively low level (lower than $25000 \mathrm{IU} / \mathrm{mL}$ ) at baseline.

$H B e A g$-positive CHB patients: At present, it is believed that quantitative HBsAg changes at 24 weeks with Peg-IFN therapy can predict a sustained response after the end of treatment and guide the treatment adjustment. Studies conducted by Sonneveld et al., ${ }^{22}$ Piratvisuth et al., ${ }^{10}$ and Neputane ${ }^{11}$ have found that the negative predictive value (NPV) of HBsAg clearance at 24 weeks after the end of treatment is $100 \%$ for $\mathrm{HBeAg}$-positive patients with quantitative $\mathrm{HBsAg}$ level of $>20000 \mathrm{IU} / \mathrm{mL}$ at 24 weeks of Peg-IFN treatment. On the other hand, HBsAg decrease to $<1500 \mathrm{IU} / \mathrm{mL}$ at 24 weeks of Peg-IFN treatment can predict sustained response after the end of treatment.

Piratvisuth et al. ${ }^{10}$ found that HBeAg seroconversion rates at 24 weeks after the end of treatment were $54 \%, 26 \%$ and $15 \%$ for patients with quantitative HBsAg level of $<1500$, 1500 to 20000 and $>20000 \mathrm{IU} / \mathrm{mL}$ at 24 weeks of Peg-IFN treatment, respectively. The Neptuane ${ }^{11}$ study showed that positive predictive value (PPV) of $\mathrm{HBeAg}$ seroconversion at 24 weeks after the end of treatment was $57 \%, 45 \%$ and 0 for patients with quantitative HBsAg level of $<1500, \leq 20000$ and $>20000 \mathrm{IU} / \mathrm{mL}$ at 24 weeks of Peg-IFN treatment, respectively. Studies have also shown that changes in HBV DNA levels during therapy can also predict sustained response at the end of therapy. Ter Borg et al. ${ }^{23}$ have found that NPV for HBsAg clearance in $\mathrm{HBeAg}$-positive patients was $100 \%$ at 24 weeks after the end of treatment, if the HBV DNA decreased $<2$ log $\mathrm{IU} / \mathrm{mL}$ at the early stage (0 to 32 weeks) of Peg-IFN treatment. Hansen et al. ${ }^{24}$ have also found that chance of HBeAg clearance and HBV DNA $<10^{5}$ copies $/ \mathrm{mL}$ at 6 months after the end of treatment disappeared if the HBV DNA decreased <2 log IU/ $\mathrm{mL}$ at 24 weeks of Peg-IFN treatment.

The 2013 NICE CHB Management Guidelines suggest that $\mathrm{HBeAg}$-positive patients should consider stopping the therapy if HBV DNA decreases <2 log IU/mL and/or HBsAg > 20000 $\mathrm{IU} / \mathrm{mL}$ at 24 weeks of Peg-IFN therapy. ${ }^{25}$ The efficacy predictive value of prolonged therapy with $\mathrm{HBsAg}$ levels at 48 weeks of Peg-IFN for HBeAg-positive patients has not been demonstrated by any research at this time. However, the safety of Peg-IFN therapy for 72 to 96 weeks has been confirmed ${ }^{26}$ and the 2017 New Switch study showed that extending Peg-IFN therapy to 96 weeks enhanced the PPV of HBsAg clearance of NA-treated $\mathrm{HBeAg}$-positive $\mathrm{CHB}$ patients. HBsAg levels decreased to $200 \mathrm{IU} / \mathrm{mL}$ at 24 weeks of Peg-IFN treatment, which is equal to $56.1 \%$ and $48.3 \%$ of patients who had not yet received $\mathrm{HBsAg}$ clearance at 48 weeks and were able to achieve HBsAg clearance during therapy prolonged to 72-96 weeks. ${ }^{27}$ Thus, it is suggested that HBeAg-positive patients with HBsAg reduced to the low level or showing sustained decrease at 48 weeks of treatment should be considered for extending Peg-IFN therapy to 72 weeks or longer.

$H B e A g$-negative $C H B$ patients: The quantitative changes in HBV DNA and HBsAg in the early stages of Peg-IFN therapy can also predict a sustained response after the end of treatment, guiding adjustment of the therapy regimen and contributing to achievement of a high treatment goal. Rijckborst et al. have found that NPV of sustained response (HBV DNA $<10000 \mathrm{IU} / \mathrm{mL}$ and ALT normal) at 24 weeks after the end of treatment reaches $100 \%$ if HBV DNA had decreased $<2 \log \mathrm{UI} / \mathrm{mL}$ at 12 weeks of Peg-IFN therapy. It is considered, however, that the results are mainly subject to genotype D and the NPV decreases to $80 \%$ for non-genotype D. Therefore, the 2013 NICE guidelines suggested that HBeAg-negative patients who received Peg-IFN therapy for 24 weeks should consider stopping the therapy if HBV DNA decreases $<2 \log \mathrm{IU} / \mathrm{mL}$ and HBsAg level remains constant.

The research developed by Moucari et al. ${ }^{28}$ for the treatment of $\mathrm{HBeAg}$-negative patients with Peg-IFN $\alpha-2 \mathrm{a}$ demonstrated that quantitative HBsAg level decreased obviously only in patients with sustained viral response (SVR). After 24 weeks of treatment, if HBsAg decreased $>1 \log \mathrm{IU} / \mathrm{mL}$, PPV of SVR was $92 \%$, while HBsAg decreased $\leq 1 \mathrm{log} \mathrm{IU} / \mathrm{mL}$ the NPV of SVR was $97 \%$. The retrospective analysis result of a Phase III clinical study in the treatment of HBeAg-negative CHB with Peg-IFN $\alpha-2$ a developed by Marcellin et al. ${ }^{13}$ showed that $56 \%$ of patients achieved a decrease $\geq 10 \%$ of $\mathrm{HBsAg}$ level at 24 weeks of treatment, with sustained response rate significantly increasing after the end of treatment compared with those patients with HBsAg decreased $<10 \%$ ( $43 \%$ vs. $13 \%, p=0.0004)$; the HBsAg clearance at 5 years after the end of treatment in patients whose HBsAg decreased $\geq 10 \%$ at 24 weeks of treatment was $22.4 \%$, which was obviously higher than in the patients whose HBsAg decreased $<10 \%$ at 24 weeks of treatment $(3.8 \%, p<0.01)$. These studies showed that for those patients with considerable decline of HBsAg level at 24 weeks of treatment and with higher certainty of SVR, Peg-IFN treatment should be continued for 48 weeks in order to achieve SVR after the end of treatment; for those patients with a modest decline of HBsAg level, the treatment could be adjusted.

The quantitative level of HBsAg at the end of the treatment also has a predictive effect on sustained response after completing treatment. The research developed by Brunetto et al. ${ }^{29}$ showed that HBsAg level decreased obviously after Peg-IFN $\alpha-2$ a treatment with or without lamivudine for 48 weeks. HBsAg level at 48 weeks of treatment predicts the sustained response of HBV DNA at 6 months after the end of treatment. After treatment for 48 weeks, the lower the HBsAg level, the higher the sustained response rate of HBV DNA after completing treatment. For those patients whose HBsAg level was $<10,<100$ and $<1000 \mathrm{IU} / \mathrm{mL}$ at the end of the treatment, the proportion of HBV DNA $<400 \mathrm{IU} / \mathrm{mL}$ at 24 weeks after the end of treatment was $88 \%, 66 \%$ and $40 \%$, respectively; in those patients whose HBsAg decreased $>1 \log \mathrm{IU} / \mathrm{mL}$ at 24 weeks of treatment while still being positive or maintaining a very low level $(<10 \mathrm{IU} / \mathrm{mL}$ ) after treatment for 48 weeks, prolonged treatment is helpful to improve efficacy, achieve sustained response and reduce recurrence rate after the end 
of treatment. Lampertico et al. ${ }^{30}$ reported that among the refractory $\mathrm{HBeAg}$-negative patients with genotype $D$, the patients whose HBsAg level was $<1000 \mathrm{IU} / \mathrm{mL}$ at 48 weeks of Peg-IFN $\alpha-2 a$ treatment were followed-up for 1 year after extended treatment for 96 weeks; the proportion of HBV DNA $<10000 \mathrm{IU} / \mathrm{mL}$ was $80 \%, 25 \%$ higher than those who received 48 weeks of treatment.

Obviously, extended Peg-IFN treatment can improve sustained response after completing treatment, and patients with low HBsAg level after 48 weeks treatment can obtain more benefits from extended Peg-IFN treatment. In addition, in the above-described research studies, $93 \%$ of the patients were refractory genotype $D$; therefore, the efficacy of extended treatment will be more desirable in patients with genotype $B$ and $C$ who have better response to Peg-IFN. In conclusion, the lower the HBsAg level after Peg-IFN treatment, the higher the probability of HBsAg clearance. Thus, for those patients with a continuous decline of HBsAg level during treatment and low HBsAg level $(<10 \mathrm{IU} / \mathrm{mL})$ at the end of treatment, the extended treatment should be considered after enquiring about the patient's willingness to obtain HBsAg clearance or seroconversion in order to achieve the ideal treatment endpoint.

Suggestion 5: The principle of treatment adjustment during treatment (i.e. response guided treatment adjustment and stopping rules).

HBeAg-positive CHB patients: At 24 weeks of treatment with Peg-IFN, if HBsAg level is $\leq 20000 \mathrm{IU} / \mathrm{mL}$, treatment should be continued to 48 weeks. For reevaluation at
Zhang W. et al: Guidelines for Peg-IFN treatment of CHB

48 weeks of treatment, if HBV DNA has dropped to the lower quantification limit, $\mathrm{HBeAg}$ seroconversion has occurred and HBsAg has decreased to a low level ( $<200 \mathrm{IU} / \mathrm{mL}$ ), the treatment can be extended to 72 weeks (no more than 96 weeks in principle), in order to pursue HBsAg clearance. If HBV DNA has dropped to the lower quantification limit and HBeAg seroconversion has not yet occurred, but HBsAg has decreased stably or been cleared at 48 weeks of treatment, the treatment can be extended to 72 weeks to pursue HBsAg seroconversion. If $\mathrm{HBeAg}$ seroconversion has not occurred and $\mathrm{HBsAg}$ has not decreased significantly at 48 weeks of treatment, it is recommended to stop the Peg-IFN and treat with NAs for long term. ${ }^{24,26}$ If HBV DNA has dropped $<2 \mathrm{log} \mathrm{IU} / \mathrm{mL}$ at 24 weeks of treatment with Peg-IFN, it is recommended to treat with a combined NA and Peg-IFN approach. If HBsAg was $>20000 \mathrm{IU} / \mathrm{mL}$ and HBV DNA dropped $<2 \mathrm{log} \mathrm{IU} / \mathrm{mL}$ at 24 weeks of treatment with Peg-IFN, it is recommended to stop Peg-IFN and treat with NAs for long term (Fig. 1).

HBeAg-negative CHB patients: If $\mathrm{HBsAg}$ has dropped $\geq 1$ $\log \mathrm{IU} / \mathrm{mL}$ at 24 weeks of treatment with Peg-IFN, it is recommended to continue treatment for 48 weeks. If HBV DNA has dropped $<2 \log \mathrm{IU} / \mathrm{mL}$ at 24 weeks of treatment with Peg-IFN, it is recommended to treat with NAs together. If HBsAg has decreased $<1 \log$ IU/mL and HBV DNA has dropped $<2 \log$ $\mathrm{IU} / \mathrm{mL}$ at 24 weeks of treatment with Peg-IFN, it is recommended to stop Peg-IFN and treat with NAs for long term. For those patients whose HBV DNA has dropped to the lower limit of detection and HBsAg has dropped to $10 \mathrm{IU} / \mathrm{mL}$ at 48 weeks of treatment with Peg-IFN, the treatment can be

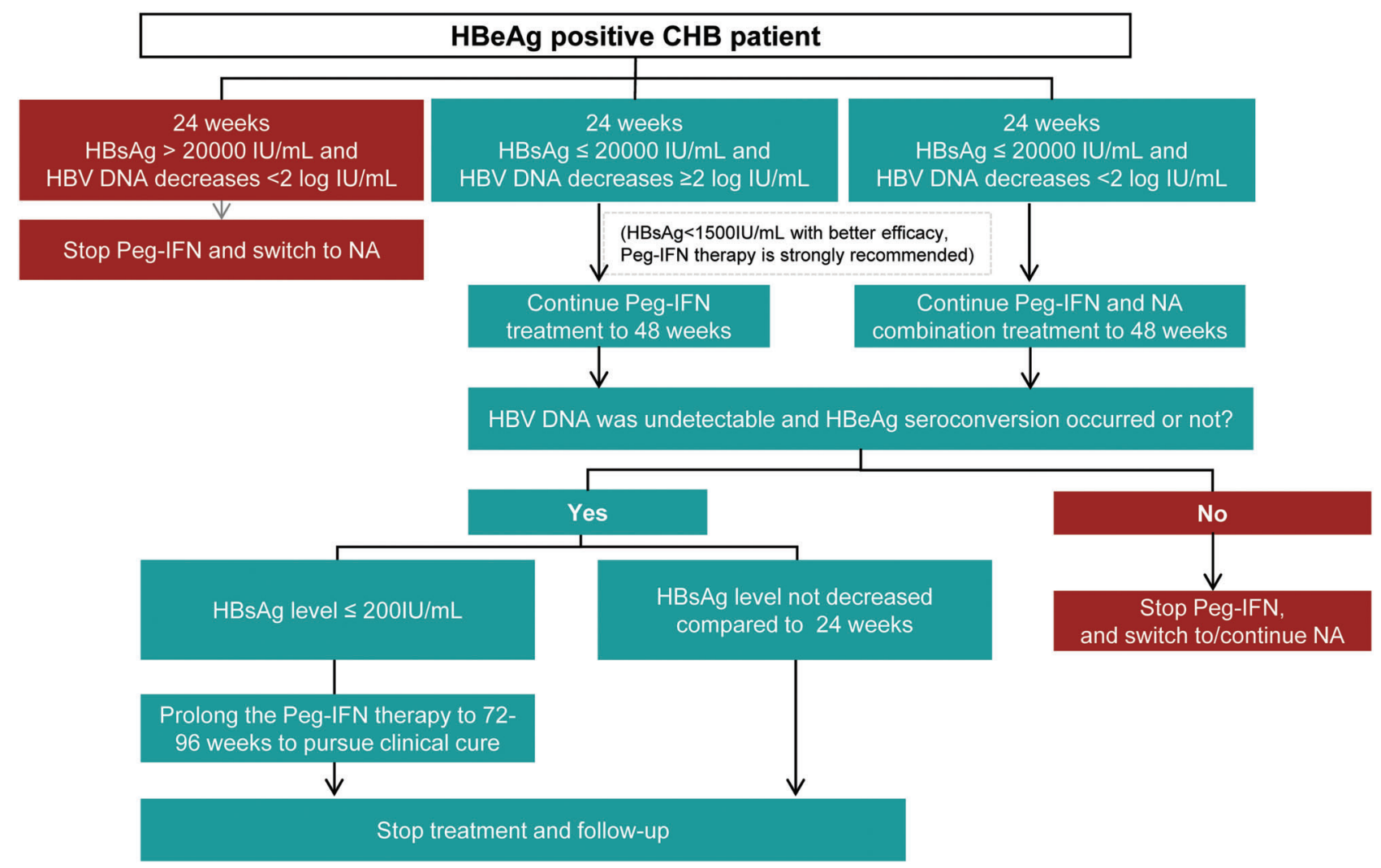

Fig. 1. Adjustment during Peg-IFN treatment for HBeAg-positive CHB patients. Abbreviations: CHB, chronic hepatitis B; NAs, nucleos(t)ide analogues; Peg-IFN, pegylated interferon. 


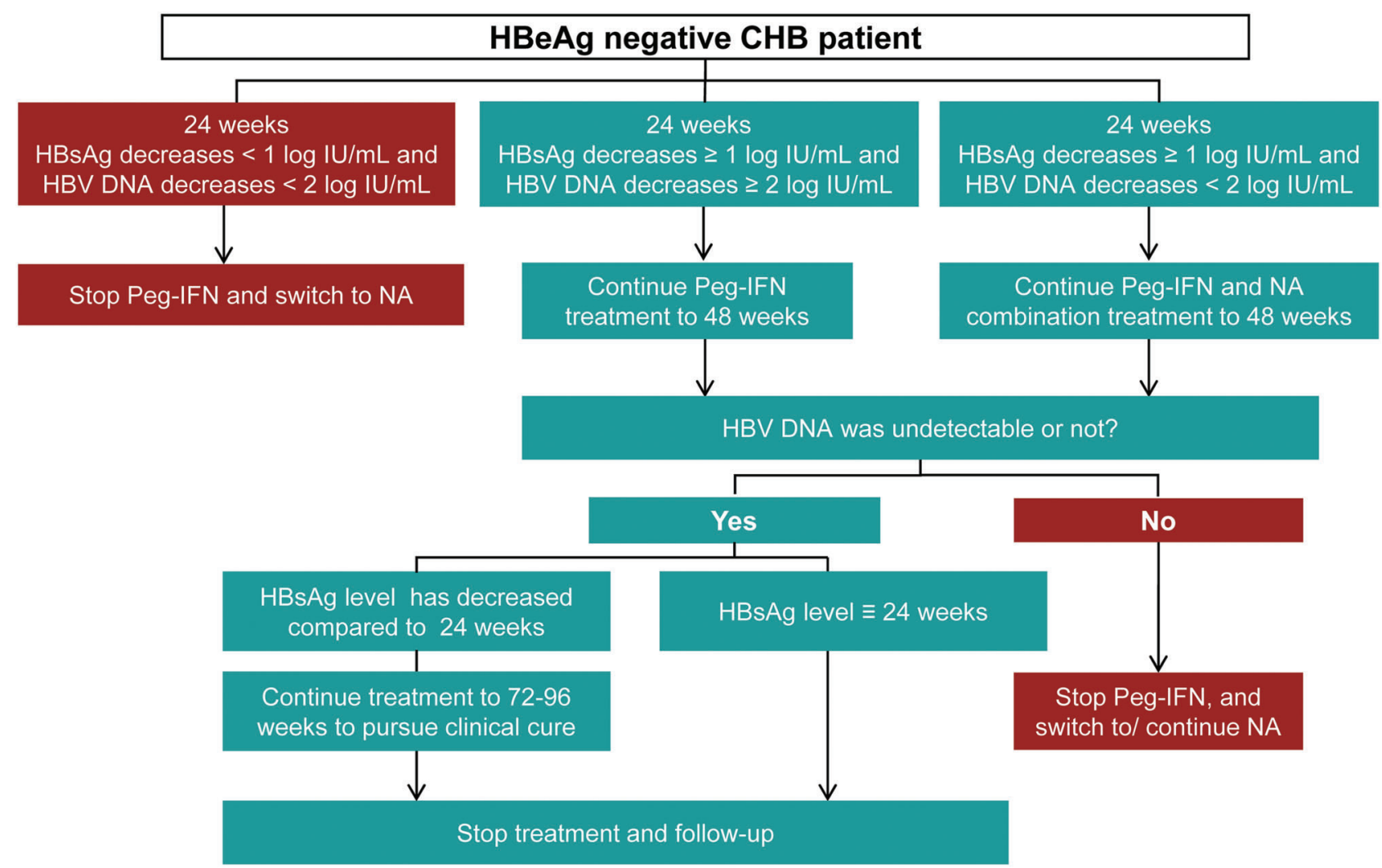

Fig. 2. Adjustment during Peg-IFN treatment for HBeAg-negative CHB patients. Abbreviations: $\mathrm{CHB}$, chronic hepatitis $B$; NAs, nucleos(t)ide analogues; Peg-IFN, pegylated interferon.

extended to 72 weeks or longer to pursue clinical cure; otherwise, it is recommended to stop Peg-IFN and treat with NAs for long term (Fig. 2).

\section{Individualized treatment strategy of NA-treated patients}

\section{Drug efficacy evaluation and NA-treated patient selection before Peg-IFN treatment}

Partial response to NAs long-term treatment includes virological response with $\mathrm{HBeAg}$ clearance or seroconversion. Those patients who had achieved a partial response showed difficulty in achievement of a sustained response after drug withdrawal. The research developed by Chaung et al. ${ }^{31}$ using 88 cases of HBeAg-positive CHB patients showed that virological relapse (HBV DNA >100 IU/mL) occurred in $90 \%$ of patients receiving NAs treatment, even for the patients with $\mathrm{HBeAg}$ seroconversion after drug withdrawal. In 2016, two research studies developed by Kim et al. ${ }^{32,33}$ determined that regardless of the $\mathrm{HBeAg}$ status, the cumulative relapse rate of patients achieving NA discontinuation standard and continuing 3 years of consolidation therapy was still above $60 \%$ for 5 years after the end of treatment.

With the advancement of clinical practice involving interferon treatment, many studies for NAs-treated patients with partial response have made great progress. In the so-called 'OSST' study developed by Ning et al., ${ }^{34} 200$ patients received continuous entecavir treatment for 9 to 36 months, with HBV DNA level $<1000 \mathrm{IU} / \mathrm{mL}$ and $\mathrm{HBeAg}<100 \mathrm{PEIU} / \mathrm{mL}$, and sequential treatment with Peg-IFN-2a for 48 weeks. The $\mathrm{HBeAg}$ seroconversion rate in the Peg-IFN $\alpha-2 a$ group was significantly higher than that in the entecavir group (14.9\% vs. $6.1 \%, p=0.0467)$. In the Peg-IFN $\alpha-2$ a group, the HBsAg clearance rate was $9.3 \%$, and in patients with baseline HBsAg ( $<1500 \mathrm{IU} / \mathrm{mL}$ ) the HBsAg clearance rate was $16.7 \%$; however, no HBsAg clearance occurred in the entecavir treatment group. In the 'NEW SWITCH' study, $303 \mathrm{HBeAg}$-positive patients with HBV DNA suppression ( $<200 \mathrm{IU} / \mathrm{mL}$ ) for 1 to 3 years after NAs treatment were treated with Peg-IFN $\alpha-2 a$ for 48 or 96 weeks randomly. The two groups of patients received NAs and PegIFN $\alpha-2 a$ combination treatment therapy in the first 12 weeks, and were followed up for 48 weeks after the end of treatment. The HBsAg clearance rate reached $16.6 \%$ and $21.3 \%$ at 48 weeks and 96 weeks of Peg-IFN $\alpha-2$ a treatment, respectively, and the HBsAg clearance rates were as high as $9.8 \%$ and $15.3 \%$ at 1 year after the end of treatment, respectively. ${ }^{27}$ The 'SWAP' mid-term analysis reported in 2017 also showed that for HBeAg-positive or -negative CHB patients who had been treated with NAs for more than 1 year and whose HBV DNA were lower than the detection limit switched to or combined with Peg-IFN $\alpha-2$ a achieved $11.4 \%$ and $9 \%$ of the $\mathrm{HBsAg}$ clearance rate, respectively, while no HBsAg clearance occurred in the NAs treatment group. During 72 weeks of follow-up, the recurrence rate was lower in the combination treatment group, ${ }^{35}$ some of who even achieved clinical cure.

These research studies have provided a theoretical basis and practice evidence for achieving higher therapeutic goals for NAs-treated patients with partial response through limited Peg-IFN treatment. Based on further analysis of the 'NEW 
SWITCH' research, it has been found that for the higher HBsAg clearance rate of $\mathrm{HBeAg}$-positive $\mathrm{CHB}$ patients with NAs treatment for 1 to 3 years, HBV DNA suppression ( $<200 \mathrm{IU} / \mathrm{mL}$ ) and baseline HBsAg $<1500 \mathrm{IU} / \mathrm{ml}$ reached $26.5 \%$ and $40 \%$ at 48 weeks or 96 weeks of Peg-IFN treatment, respectively. ${ }^{27}$ The OSST research also showed that $33.3 \%$ and $22.2 \%$ of patients with $\mathrm{HBeAg}$ clearance and $\mathrm{HBsAg}<1500 \mathrm{IU} / \mathrm{mL}$ who had switched to Peg-IFN $\alpha$-2a therapy achieved HBeAg seroconversion and of HBsAg clearance, respectively. ${ }^{34}$ Therefore, for those patients treated with NAs who obtained HBV DNA inhibition, $\mathrm{HBeAg}$ clearance and $\mathrm{HBsAg}<1500 \mathrm{IU} / \mathrm{mL}$, the treatment was considered as Peg-IFN sequential therapy to pursue HBsAg clearance and achieve clinical cure.

Suggestion 6: The sequential combination Peg-IFN strategy had a higher chance of achieving satisfactory, ideal therapy and for pursuing clinical cure for a portion of NAtreated patients, as discussed below.

If HBV DNA is undetectable and $\mathrm{HBeAg}$ is $<100 \mathrm{PEIU} / \mathrm{mL}$, the sequential combination with Peg-IFN is able to achieve higher rate of $\mathrm{HBeAg}$ seroconversion. On this basis, the clearance of HBsAg can be further pursued according to the condition of the patient. If HBV DNA is undetectable, HBsAg is $<1500 \mathrm{IU} / \mathrm{mL}$ and $\mathrm{HBeAg}$ has disappeared, the sequential combination with Peg-IFN can achieve higher HBsAg clearance rate. Therapy should be adjusted according to the response during treatment (refer to Suggestion 7).

\section{Adjustments for NA-treated patients during the Peg-IFN treatment}

For patients treated with NAs, besides the baseline $\mathrm{HBsAg}$ level, HBsAg changes in early Peg-IFN sequential or combination therapy can also predict response, which is beneficial for adjusting the treatment regimen or prolonging the duration of treatment, so as to improve the sustained response rate and save medical resources. NEW SWITCH research verified that the HBsAg clearance rate in patients with $\mathrm{HBsAg}<200 \mathrm{IU} / \mathrm{mL}$ or that had dropped $\geq 1 \log \mathrm{IU} / \mathrm{mL}$ at 24 weeks of Peg-IFN sequential treatment reached $47.8 \%$ or $56.1 \%$ at 48 weeks or 96 weeks of treatment, respectively. On the contrary, the NPV of $\mathrm{HBsAg}$ clearance in patients with $\mathrm{HBsAg} \geq 200 \mathrm{IU} / \mathrm{mL}$ and that had dropped $<1 \log \mathrm{IU} / \mathrm{mL}$ at 24 weeks of Peg-IFN sequential treatment was $100 \%$ or $96.4 \%$ at 48 weeks or 96 weeks of treatment, respectively. ${ }^{27}$ The OSST study also showed that patients with $\mathrm{HBsAg}<200 \mathrm{IU} / \mathrm{mL}$ at 12 weeks of Peg-IFN sequential treatment achieved the best efficacy (HBeAg seroconversion rate of $66.7 \%$, and $\mathrm{HBsAg}$ clearance rate up to $77.8 \%$ ). On the contrary, the HBsAg clearance rate in patients with $\mathrm{HBsAg} \geq 1500 \mathrm{IU} / \mathrm{mL}$ at 12 weeks of treatment was only $1.7 \%{ }^{34}$ Both the SWAP mid-term analysis and the Japanese Red Cross Hospital cohort study showed that early decrease of HBsAg can accurately predict the long-term response in Peg-IFN combined or sequential therapy. ${ }^{35,36}$

Suggestion 7: For NA-treated patients, if HBsAg is $<200$ $\mathrm{IU} / \mathrm{mL}$ or drops $\geq 1 \mathrm{log} \mathrm{IU} / \mathrm{mL}$ at 24 weeks of Peg-IFN combined or sequential therapy, it is recommended to continue Peg-IFN therapy to 48 weeks; if $\mathrm{HBsAg}$ is $\geq 200 \mathrm{IU} / \mathrm{mL}$ or drops $<1 \mathrm{log}$ $\mathrm{IU} / \mathrm{mL}$ at 24 weeks of treatment, the treating clinician should decide whether to continue the treatment according to the change of HBeAg. If the HBeAg has decreased obviously or cleared/seroconverted, it is recommended to continue with the Peg-IFN therapy to 48 weeks, otherwise stop the Peg-IFN and treat patients with NA for long term. If the HBsAg has cleared at 48 weeks of treatment, stop treatment and follow up; if not, extend the Peg-IFN treatment to 72 or 96 weeks, as alternative. If $\mathrm{HBsAg}$ clearance or $\mathrm{HBeAg}$ seroconversion can be achieved, stop treatment and follow up; otherwise, stop Peg-IFN and treat patients with NA for long term (Fig. 3).

Peg-IFN treatment strategy for the population with high risk of HCC

\section{Baseline liver cancer in high-risk patients with CHB}

In the natural history of $\mathrm{CHB}$, the annual incidence rate of $\mathrm{HCC}$ in $\mathrm{CHB}$ patients with non liver cirrhosis ranges from $0.5 \%$ to $1 \%$, and with cirrhosis ranges from $3 \%$ to $6 \%,{ }^{5}$ which is far higher than the general population and the incidence of liver cancer in China $(0.026 \%){ }^{37}$ Interferon has a variety of biological functions, including antiviral, antiproliferation, antiangiogenesis and immunomodulatory effects, and interferon can also achieve its antitumor effect ${ }^{38}$ by inhibiting tumor angiogenesis and antitumor cell proliferation.

A retrospective cohort study in Taiwan showed that the cumulative incidence of HCC in the Peg-IFN treatment group was significantly lower than that in the entecavir treatment group $(p=0.022)$. When the baseline age of the patients was matched for analysis, Peg-IFN treatment was found to significantly reduce the risk of HCC in patients with $\mathrm{CHB}$ by $90 \%$ (baseline matched population correction $\mathrm{HR}=0.103$, $p=0.031$ ) compared with NAs. ${ }^{39}$ Similarly, from the prospective cohort study of Lim et al., ${ }^{35}$ the incidence of liver cirrhosis in $\mathrm{HBeAg}$-positive patients treated with Peg-IFN $\alpha$ was found to be significantly lower than that of patients treated with entecavir ( $p=0.044$ ); based on the REACH-B model, the incidence of HCC in patients treated with Peg-IFN $\alpha$ was lower than expected ( $p=0.038)$, while in the entecavir group this effect was not observed $(p=0.36)$. However, this conclusion should be verified by more findings with evidence-based medicines.

Suggestion 8: $\mathrm{CHB}$ is a risk factor for $\mathrm{HCC}$, and the $\mathrm{CHB}-$ related liver cirrhosis is a high-risk factor for $\mathrm{HCC}$. For patients with high-risk factors of HCC, the Peg-IFN antiviral therapy is recommended, if no contraindication of interferon exists.

\section{Patients after HCC resection}

Currently, resection is still the preferred method for treating primary $\mathrm{HCC}^{40}$ but the recurrence rate of $\mathrm{HCC}$ after radical resection is reportedly $61.5 \%$ in 5 years, which represents a problem in the clinical treatment of HCC and significantly affects the long-term efficacy of HCC treatment and its prognosis. ${ }^{40}$ The virologic factors in circulation of HBV-related HCC recurrence is HBV load, so the application of antiviral therapy in patients with HBV-related HCC has clinical significance. ${ }^{41}$ On the other hand, it has been widely accepted that metastasis and recurrence of tumor are not only associated with tumor cells, but also affected critically by the microenvironment in an immunosuppressive state through immunoediting. ${ }^{42,43}$

Interferon has an effect on HBV DNA suppression, immunoregulation, inhibition of malignant cell proliferation and antiangiogenesis, which provide a solid theoretical basis for prevention of recurrence after HBV-related HCC resection. ${ }^{38,44}$ Systematic review and meta-analysis in 2016 also confirmed that interferon-alpha adjuvant therapy significantly reduced the recurrence of $\mathrm{HBV}$-related $\mathrm{HCC}$ surgery/interventional therapy $(R R=0.90, p=0.02)$ and mortality risk $(R R=0.72$, $p=0.001)$, as compared with the placebo control group. 


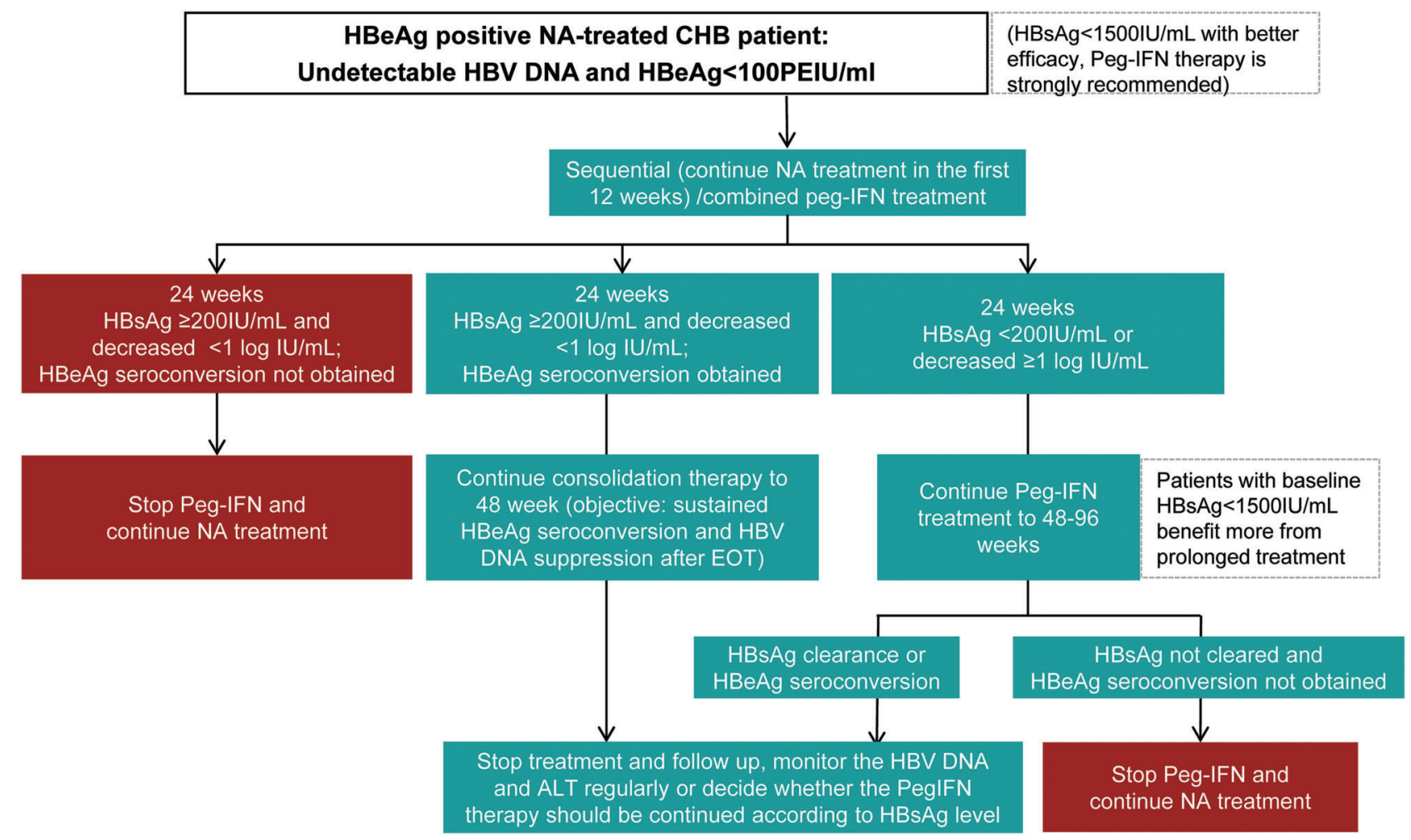

Fig. 3. Adjustment during Peg-IFN treatment for NA-treated CHB patients. Abbreviations: CHB, chronic hepatitis B; NAs, nucleos(t)ide analogues; Peg-IFN, pegylated interferon.

This benefit is more significant after hepatic arterial chemoembolization or hepatic arterial chemoembolization combined surgical treatment. ${ }^{38}$ The "Expert Consensus on Antiviral Therapy to Hepatitis B/C Virus-Related Hepatocellular Carcinoma" published in 2014 also stressed that in the synthesized project of HBV-related HCC patients, interferon-alpha adjuvant therapy can be chosen if no contraindications exist $(1, A) .{ }^{41}$

Suggestion 9: Interferon alpha (including Peg-IFN $\alpha$ ) is recommended to be used as adjuvant therapy to reduce and prevent the postoperative recurrence of HCC in patients with HBV-related HCC who have been treated with surgery, intervention and ablation, and who are without interferon contraindication.

\section{Children with CHB}

Compared with adults, children with $\mathrm{CHB}$ have similarities that highlight its distinctive particularity. HBV infection in the infantile period has a stronger immunological tolerance, and the earlier the age of HBV infection, the sooner and more likely the virus is to form immune tolerance. The incidence of chronic HBV infection is highest in the perinatal period $(90 \%)$ compared to the toddler period $(30 \%)$ or adulthood ( $5 \%$ to $10 \%) .{ }^{45}$ People with HBV infection in the immune tolerant phase are known as chronic HBV carriers, and they usually have high levels of HBV DNA, but ALT and aspartate aminotransferase (AST) in the normal range, and no pathological changes or minor lesions found in the liver biopsy examination. Therefore, HBV carriers are now considered as having no indications for antiviral therapy.
However, a few young children can present clinically with ALT elevation and other immune activity, and the reports about treating them with antiviral therapy are increasing year by year. Zhang ${ }^{46}$ showed that in 506 cases of children with CHB treated by interferon alpha, the HBeAg-negative turning rate was $36.5 \%$ at the end of the treatment, higher than in the adult patients in the same period (32.3\%); the HBV DNAnegative turning rate (that is, lower than the lower limit of detection) was $15.4 \%$ (with $15.03 \%$ of adult patients in the same period). After follow-up, liver pathological lesion inflammatory activity grades were significantly restored and liver active lesions and recurrent illness were under control; thus, children were considered less likely than adult patients to experience adverse reactions. Zhu et al. ${ }^{45}$ retrospectively analyzed the HBsAg clearance rate of 293 children with HBeAg-positive $\mathrm{CHB}$ who were $1-7$ years old and treated with interferon antiviral therapy. Follow-up for at least 6 months after the drug withdrawal showed that the children treated with interferon alone were able to achieve a $48.8 \%$ HBsAg clearance rate. Moreover, despite the low level of ALT before treatment and high load of HBV DNA, the HBsAg clearance rate could go higher. The study suggested that children with $\mathrm{HBeAg}$-positive $\mathrm{CHB}$ have a higher HBsAg clearance rate upon receiving interferon-based antiviral therapy before age 7.

Similar studies have also shown that ALT elevation $(>2 \times$ ULN), low HBV DNA load, female sex, and age less than 5 years associated with obtainment of a higher response rate from interferon alpha therapy, suggesting these factors can be used to determine the more appropriate population of interferon alpha. ${ }^{4}$ Treating children with $\mathrm{CHB}$ with interferon 
alpha usually requires the selection of interferon dosage $\mathrm{s}^{5}$ based on body surface area. In order to optimize the child's administration, Sarr et $a .^{47}$ studied the effects of selecting Peg-IFN $\alpha$ dose based on body surface area of 3- to 18-yearold patients with $\mathrm{CHB}$ using pharmacokinetic parameters, and found that $0.51-0.53 \mathrm{~m}^{2}, 0.54-0.74 \mathrm{~m}^{2}, 0.75-1.08 \mathrm{~m}^{2}$, $1.09-1.51 \mathrm{~m}^{2}$ and $>1.51 \mathrm{~m}^{2}$ patients were given $45 \mathrm{\mu g} /$ week, $65 \mu \mathrm{g} /$ week, $90 \mu \mathrm{g} /$ week, $135 \mu \mathrm{g} /$ week and $180 \mu \mathrm{g} /$ week Peg-IFN, respectively, which can reach similar pharmacokinetic properties as in adults, and suggest that the selection of appropriate dosage based on body surface area is feasible for children with $\mathrm{CHB}$ administration.

Suggestion 10: Interferon alpha (including Peg-IFN $\alpha$ )oriented treatment regimen could be selected for antiviral treatment of children with CHB. Due to different ages, different individual compliance and differences in lesions etc., the antiviral drug selection and individualized treatment regimen of children is more important than that of adults who are $\mathrm{CHB}$ patients. Interferon alpha (including Peg-IFN $\alpha$ ) could be used as first-line treatment for children without active lesions and contraindications or cautions for interferon alpha. Children with ALT elevated ( $>2 \times$ ULN), low HBV DNA level, female sex and $<5$ years of age have better response to IFN.

\section{Monitoring, follow-up and adverse reaction management during Peg-IFN treatment}

The monitoring and follow-up of antiviral $\mathrm{CHB}$ are important issues in clinical practice, and the relative technique for both is clearly stated in relevant technical specifications. Because different patients have different response times and drug tolerances, and many other differences related to the interferon treatment, it is very important to closely monitor and follow-up during interferon treatment. ${ }^{2,5}$ Before initiating interferon therapy, measurement of key baseline parameters is required to predict efficacy and safety, such as precise evaluation of the HBsAg quantity, HBV DNA level and normal levels of aminotransferases, liver ultrasound and FibroScan, mental condition, thyroid function and associated antibodies and lung disease, ${ }^{48}$ which is significant for determining the severity of adverse events and whether there is response to therapy. Monitoring shall be carried out periodically for adverse events and the efficacy index during the treatment, where adverse events will be monitored mainly at the beginning of treatment and efficacy index monitoring shall be combined in the later stage. ${ }^{2,5}$

As for ALT elevation at the initial treatment period, $\mathrm{HBsAg}$ quantity and HBV DNA level changes will be combined for specific analysis and correct understanding. Timely communication with patients shall be conducted for understanding and cooperation. In general, patients with response may experience ALT elevation when they experience decreased HBV DNA and decreased HBsAg quantity. Accordingly, ALT elevation is an important efficacy monitoring index and shall be monitored closely. As for patients with realization of endpoint of treatment, periodical follow-up visits shall be done once in 3 months at the start, and the time interval of the follow-up visits can be gradually extended for patients without recurrence beyond 6 months. If there is any recurrence detected during the follow-up, retreatment is still effective. ${ }^{2,5}$

Adverse events of interferon have great influence on treatment compliance. As for adverse events and disposal of interferon, there is clear explanation in China's CHB
Prevention and Treatment Guidelines and they play great guiding and reference roles in clinic. The adverse events at the beginning of interferon treatment mainly include influenza-like symptoms (fever, muscular soreness or joint sore) and one-time peripheral blood counts change. Influenza-like symptoms can be relieved and even completely resolved with time extension of treatment. In severe cases, expectant treatment can be made, and there are few patients who discontinue the treatment because of it. The most common reason for discontinuing treatment is decreased peripheral blood count (including neutrophils) and blood platelets. Generally, symptoms can be relieved with expectant treatment or adjustment of dosage. ${ }^{5}$ According to experience of clinicians, Chinese patient weight is lower than patients in Europe and America, so standard dosage cannot be prescribed directly. Patients with average weight, lower dosage or extension of dosing interval can be taken into account for determining safety and effectiveness.

Suggestion 11: As for monitoring and follow-up visits in Peg-IFN $\alpha$ treatment, the baseline level measurement of key indexes shall be made before treatment, including HBV DNA quantity, $\mathrm{HBeAg}$ and $\mathrm{HBsAg}$ (as quantitative or semiquantitative), ALT and AST, total bilirubin and direct bilirubin, and routine blood test. Liver ultrasound or computed tomography examination, double-lung imageological examination and fundus examination shall be made and fasting blood glucose, thyroid function or thyroid autoantibodies [thyrotropic hormone (TSH), free triiodothyronine, free thyroxine, thyroglobulin antibodies, thyroid peroxidase antibody] and so on shall be examined. If interferon treatment is considered for patients with obviously higher ALT level $(>10 \times$ ULN) and the interferon therapy for patients with normal total bilirubin and direct bilirubin, such treatment shall be carried out or guided by experts with strong clinical experience. When using interferon, the adverse events of drugs shall be monitored closely, and expectant treatment and supportive treatment could be beneficial. If ALT level starts to decrease or has decreased to $<10 \times$ ULN and there is no significant increase in bilirubin, then interferon treatment can be initiated. Normal dosage or lower dosage can be used according to conditions of the patients. Routine blood test will be made once a week after starting treatment and disposal will be made properly according to changes (see Suggestion 12 for understanding and processing of adverse events); according to monitoring, interval time can be extended gradually after the index becomes stale or shows improvement within a month. In the first 3 months following treatment, ALT, HBV DNA, HBsAg and HBeAg shall be monitored once a month and the monitoring interval time can be extended after these parameters become significantly decreased or normal. HBeAg and anti-HBe quantitative or semi-quantitative changes of patients with positive $\mathrm{HBeAg}$ shall be monitored, and in the meantime, there should be monitoring for whether any adverse events of interferon occur. B-mode ultrasound inspection shall be made every 6 months. At the beginning, follow-up visits can be made once a month, and the follow-up visit interval time can be extended gradually after 3 months. A follow-up visit of every 3-6 months can be made for patients with response and stable conditions.

Suggestion 12: For understanding and processing of Peg-IFN adverse events, if there is influenza-like illness, including fever, headache, muscle pain and weakness, PegIFN can be injected before sleep or an analgesic-antipyretic can be taken at the same time. Peripheral blood routine changes shall be monitored closely. If neutrophil granulocytes 
are $\leq 0.75 \times 10^{9} / \mathrm{L}$ and (or) blood platelets are $<50 \times 10^{9} / \mathrm{L}$, Peg-IFN dosage shall be reduced and re-examination shall be made within 1-2 weeks. If the numbers are restore, the original dosage will be introduced gradually; if neutrophil granulocytes are $\leq 0.5 \times 10^{9} / \mathrm{L}$ and (or) blood platelets are $<25 \times$ $10^{9} / \mathrm{L}$, Peg-IFN shall be stopped. Granulocyte colony stimulating factor or granulocyte-macrophage colony stimulating factor treatment can be tried for patients with significant decrease of neutrophil granulocytes. Patients receiving interferon treatment should receive close monitoring for possible depressive symptoms, such as depression, delusion, severe anxiety and so on. Expectant treatment can be given in minor depression; patients with worse depressive symptoms should consult a psychiatrist, and interferon treatment shall be instantly suspended for severe insanity. Some patients may have autoantibodies and only a few patients have thyroid disease, diabetes, decrease platelet count, psoriasis, vitiligo, rheumatoid arthritis and systemic lupus erythematosus syndrome. When the said symptom occurs, the patient shall be diagnosed and treated by the relative clinics, and patients with severe symptoms shall discontinue the drug. Thyroid function or thyroid autoantibodies and other relevant indicators, as well as associated symptoms of thyroid disease, shall be monitored periodically (see Suggestion 11). Patients with normal TSH and negative thyroid autoantibodies shall be monitored once every 3 months until the end of interferon treatment; reasons for abnormal TSH in patients shall be determined and processed in a timely manner. In general, thyroxine treatment and interferon treatment can be initiated at the same time for patients with hypothyroidism and mild Grave's disease, but shall be monitored closely. Patients with sudden occurrence of severe thyroid disease in the treatment shall be treated by the relevant specialist and, if necessary, interferon treatment can be discontinued. Peg-IFN treatment should be stopped in the case of renal damage, cardiovascular complication, retinopathy, hearing loss and interstitial pneumonia.

\section{Problems remaining to be solved for Peg-IFN treatment}

Most data comes from Caucasian populations, and there is not enough evidence of treatment for CHB patients infected with genotype B or C. Nowadays, more attention is paid to patient selection, treatment adjustment and the stopping rule of PegIFN $\alpha$ therapy. Therefore, more studies on Chinese patients are needed to answer the following questions: (1) What is the cut-off value of HBsAg at 48 weeks or 72 weeks of Peg-IFN treatment when pursuing $\mathrm{HBsAg}$ clearance? (2) What is the range of the degree of HBsAg decline in $\mathrm{HBeAg}$-negative $\mathrm{CHB}$ patients, and could it predict the treatment response? (3) Is the initial combination therapy of NA and Peg-IFN valuable, and what is the advantage of pharmacoeconomics for the sequential Peg-IFN $\alpha$ therapy in NA-treated patients? (4) How to individualize the prolonged Peg-IFN treatment? (5) Is it necessary to treat nonactive HBsAg carriers? (6) Does interferon therapy have more advantages for reducing incidence rate of liver cancer than NA antiviral therapy? (7) What is the dosage and duration of Peg-IFN for the postoperative patients with hepatic cancer?

Experts participating in the seminar: Xinyue Chen, Xiaoguang Dou, Zhiliang Gao, Peng Hu, Jiaji Jiang, Hong Ren, Jia Shang, Guiqiang Wang, Qing Xie, Yao Xie, Yida Yang, Dazhi Zhang, Hongfei Zhang, Wenhong Zhang.

\section{Conflict of interest}

The authors have no conflict of interests related to this publication.

\section{References}

[1] Wan $M$, Weng $X$. Several supplements on recommendation of interferon therapy for chronic hepatitis B. Chin J Infect Dis 2012;30:705-710. doi: 10.3760/cma.j.issn.1000-6680.2012.12.001.

[2] Wan M, Weng X. Expert advices for interferon treatment of chronic hepatitis B (2010 update). Chin J Infect Dis 2010;28:193-200. doi: 10.3760/cma.j.issn. 1000-6680.2010.04.001.

[3] Terrault NA, Bzowej NH, Chang KM, Hwang JP, Jonas MM, Murad MH. AASLD guidelines for treatment of chronic hepatitis B. Hepatology 2016;63: 261-283. doi: 10.1002/hep.28156.

[4] Sarin SK, Kumar M, Lau GK, Abbas Z, Chan HL, Chen CJ, et al. Asian-Pacific clinical practice guidelines on the management of hepatitis $B$ : a 2015 update. Hepatol Int 2016;10:1-98. doi: 10.1007/s12072-015-9675-4.

[5] Hou JL, lai W. The guideline of prevention and treatment for chronic hepatitis B: a 2015 update. Zhonghua Gan Zang Bing Za Zhi 2015;23: 888-905. doi: 10.3760/cma.j.issn.1007-3418.2015.12.002.

[6] EASL 2017 Clinical Practice Guidelines on the management of hepatitis B. virus infection. J Hepatol 2017;67:370-398. doi: 10.1016/j.jhep.2017. 03.021.

[7] Chan $\mathrm{HL}$, Wong VW, Tse AM, Tse $\mathrm{CH}$, Chim AM, Chan HY, et al. Serum hepatitis B surface antigen quantitation can reflect hepatitis $B$ virus in the liver and predict treatment response. Clin Gastroenterol Hepatol 2007;5: 1462-1468. doi: 10.1016/j.cgh.2007.09.005.

[8] Tseng TC, Liu CJ, Yang HC, Su TH, Wang CC, Chen CL, et al. Serum hepatitis B surface antigen levels help predict disease progression in patients with low hepatitis B virus loads. Hepatology 2013;57:441-450. doi: 10.1002/hep. 26041.

[9] Liu F, Wang XW, Chen L, Hu P, Ren H, Hu HD. Systematic review with metaanalysis: development of hepatocellular carcinoma in chronic hepatitis $B$ patients with hepatitis B surface antigen seroclearance. Aliment Pharmacol Ther 2016;43:1253-1261. doi: 10.1111/apt.13634.

[10] Piratvisuth T, Marcellin P, Popescu M, Kapprell HP, Rothe V, Lu ZM. Hepatitis B surface antigen: association with sustained response to peginterferon alfa$2 a$ in hepatitis B e antigen-positive patients. Hepatol Int 2013;7:429-436. doi: 10.1007/s12072-011-9280-0.

[11] Liaw YF, Jia JD, Chan HL, Han KH, Tanwandee T, Chuang WL, et al. Shorter durations and lower doses of peginterferon alfa-2a are associated with inferior hepatitis $B$ e antigen seroconversion rates in hepatitis $B$ virus genotypes B or C. Hepatology 2011;54:1591-1599. doi: 10.1002/hep.24555.

[12] Yang $S$, Xing $H$, Wang $Y$, Hou J, Luo $D$, Xie $Q$, et al. HBsAg and HBeAg in the prediction of a clinical response to peginterferon $\alpha-2 b$ therapy in Chinese HBeAg-positive patients. Virol J 2016;13:180. doi: 10.1186/s12985-0160640-1.

[13] Marcellin P, Bonino F, Yurdaydin C, Hadziyannis S, Moucari R, Kapprell HP, et al. Hepatitis $B$ surface antigen levels: association with 5 -year response to peginterferon alfa-2a in hepatitis $B$ e-antigen-negative patients. Hepatol Int 2013;7:88-97. doi: 10.1007/s12072-012-9343-x.

[14] Lau GK, Piratvisuth T, Luo KX, Marcellin P, Thongsawat S, Cooksley G, et al. Peginterferon Alfa-2a, lamivudine, and the combination for HBeAg-positive chronic hepatitis B. N Engl J Med 2005;352:2682-2695. doi: 10.1056/ NEJMoa043470.

[15] Lau GKK, Piratvisuth T, Luo KX, Marcellin P, Thongsawat S, Cooksley G, et al. Durability of response and occurrence of late response to peginterferon alpha-2a (4OKD) [PEGASYS] one year post-treatment in patients with HBeAg-positive chronic hepatitis B. J Hepatol 2006;44:S23-S24. doi: 10. 1016/S0168-8278(06)80051-6.

[16] Chuang WL, Jia J, Chan HLY, Han KH, Tanwandee T, Tan D, et al. FRI-148 $\mathrm{HBeAg}$ seroconversion rates after five years of follow-up in patients treated with peginterferon alfa-2a (40kd) in neptune: final results of the son of neptune long-term follow-up study. J Hepatol 2016;64:S604. doi: 10. 1016/S0168-8278(16)01116-8

[17] Stelma F, van der Ree MH, Jansen L, Peters MW, Janssen HLA, Zaaijer HL, et al. HBsAg loss after peginterferon-nucleotide combination treatment in chronic hepatitis B patients: 5 years of follow-up. J Viral Hepat 2017;24: 1107-1113. doi: 10.1111/jvh.12738.

[18] EASL clinical practice guidelines: Management of chronic hepatitis $B$. virus infection. J Hepatol 2012;57:167-185. doi: 10.1016/j.jhep.2012.02.010.

[19] Buster EH, Hansen BE, Lau GK, Piratvisuth T, Zeuzem S, Steyerberg EW, et al. Factors that predict response of patients with hepatitis $B$ e antigenpositive chronic hepatitis B to peginterferon-alfa. Gastroenterology 2009; 137:2002-2009. doi: 10.1053/j.gastro.2009.08.061. 
[20] Chan HLY, Messinger D, Papatheodoridis GV, Cornberg M, Xie Q, Piratvisuth T, et al. A genotype-specific baseline score to predict post-treatment response to peginterferon alfa-2a in $\mathrm{HBeAg}$-positive patients with hepatitis B virus genotype B or C infection. J Hepatol 2016;64:S589-S590. doi: 10.1016/ S0168-8278(16)01085-0.

[21] Wang YC, Yang SS, Su CW, Wang Y], Lee KC, Huo TI, et al. Predictors of response to pegylated interferon in chronic hepatitis $\mathrm{B}$ : a real-world hospital-based analysis. Sci Rep 2016;6:29605. doi: 10.1038/srep29605.

[22] Sonneveld MJ, Hansen BE, Piratvisuth T, Jia JD, Zeuzem S, Gane E, et al. Response-guided peginterferon therapy in hepatitis $B$ e antigen-positive chronic hepatitis B using serum hepatitis B surface antigen levels. Hepatology 2013;58:872-880. doi: 10.1002/hep.26436.

[23] ter Borg MJ, van Zonneveld M, Zeuzem S, Senturk H, Akarca US, Simon C, et al. Patterns of viral decline during PEG-interferon alpha-2b therapy in HBeAg-positive chronic hepatitis B: relation to treatment response. Hepatology 2006;44:721-727. doi: 10.1002/hep.21302.

[24] Hansen BE, Buster EH, Steyerberg EW, Lesaffre E, Janssen HL. Prediction of the response to peg-interferon-alfa in patients with $\mathrm{HBeAg}$ positive chronic hepatitis B using decline of HBV DNA during treatment. J Med Virol 2010;82: 1135-1142. doi: 10.1002/jmv.21778.

[25] Hepatitis B (chronic): diagnosis and management of chronic hepatitis B in children, young people and adults. London: National Institute for Health and Care Excellence (UK), 2013.

[26] Sun J, Ma H, Xie Q, Xie Y, Sun $Y$, Wang $H$, et al. Response-guided peginterferon therapy in patients with $\mathrm{HBeAg}$-positive chronic hepatitis $\mathrm{B}$ : A randomized controlled study. J Hepatol 2016;65:674-682. doi: 10.1016/j.jhep. 2016.05.024.

[27] Hu P, Dou X, Xie Q. High HBsAg loss rate in HBeAg loss CHB patients SWITCH from NUC to Peg-IFN alfa-2a (NEW SWITCH study). Hepatol Int 2017;11: S1-S1093.

[28] Moucari R, Mackiewicz V, Lada O, Ripault MP, Castelnau C, Martinot-Peignoux $M$, et al. Early serum HBsAg drop: a strong predictor of sustained virological response to pegylated interferon alfa-2a in HBeAg-negative patients. Hepatology 2009;49:1151-1157. doi: 10.1002/hep.22744.

[29] Brunetto MR, Moriconi F, Bonino F, Lau GK, Farci P, Yurdaydin C, et al. Hepatitis $B$ virus surface antigen levels: a guide to sustained response to peginterferon alfa-2a in $\mathrm{HBeAg}$-negative chronic hepatitis B. Hepatology 2009;49:1141-1150. doi: 10.1002/hep.22760.

[30] Lampertico P, Viganò M, Di Costanzo GG, Sagnelli E, Fasano M, Di Marco V, et al. Randomised study comparing 48 and 96 weeks peginterferon $\alpha-2 a$ therapy in genotype D HBeAg-negative chronic hepatitis B. Gut 2013;62: 290-298. doi: 10.1136/gutjnl-2011-301430.

[31] Chaung KT, Ha NB, Trinh HN, Garcia RT, Nguyen HA, Nguyen KK, et al. High frequency of recurrent viremia after hepatitis $\mathrm{B}$ e antigen seroconversion and consolidation therapy. J Clin Gastroenterol 2012;46:865-870. doi: 10 . 1097/MCG.0b013e31825ceed9.

[32] Kim JK, Lee KS, Lee JI, Kang AY, Chang HY. Outcome of 3-year consolidation therapy following $\mathrm{HBeAg}$ loss in $\mathrm{HBeAg}$-positive chronic hepatitis $\mathrm{B}$ patients treated with nucleos(t)ide analogues. J Hepatol 2016;64:S592. doi: 10. 1016/S0168-8278(16)01091-6.

[33] Kim J, Yu J, Lee J. Durability of 3-year consolidation therapy following virologic response in chronic hepatitis $B$ patients treated with nuclios(t)ide analogues. Hepatology $2016 ; 63: 928$ A.
[34] Ning Q, Han M, Sun Y, Jiang J, Tan D, Hou J, et al. Switching from entecavir to PegIFN alfa-2a in patients with $\mathrm{HBeAg-positive} \mathrm{chronic} \mathrm{hepatitis} \mathrm{B}$ : a randomised open-label trial (OSST trial). J Hepatol 2014;61:777-784. doi: 10. 1016/j.jhep.2014.05.044.

[35] Lim SG, Yang WL, Ngu J, Tan J, Ahmed T, Dan YY, et al. Switch or add-on peginterferon for chronic hepatitis $B$ patients already on nucleos(t)ide analogue therapy (SWAP study): provisional analysis - add-on therapy superior. J Hepatol 2017;66:S60. doi: 10.1016/S0168-8278(17)30382-3.

[36] Tamaki N, Kurosaki M, Kusakabe A, Orito E, Joko K, Kojima Y, et al. Hepatitis B surface antigen reduction by switching from long-term nucleoside/nucleotide analogue administration to pegylated interferon. J Viral Hepat 2017;24: 672-678. doi: 10.1111/jvh.12691.

[37] Zuo TT, Zheng RS, Zhang SW, Zeng HM, Chen WQ. Incidence and mortality of liver cancer in China in 2011. Chin J Cancer 2015;34:508-513. doi: 10. 1186/s40880-015-0056-0.

[38] Yang S, Lin Q, Lin W, Hu W, Wang G. Effect of adjuvant interferon therapy on hepatitis B virus-related hepatocellular carcinoma: a systematic review. World J Surg Oncol 2016;14:159. doi: 10.1186/s12957-016-0912-7.

[39] Liang KH, Hsu CW, Chang ML, Chen YC, Lai MW, Yeh CT. Peginterferon is superior to nucleos(t)ide analogues for prevention of hepatocellular carcinoma in chronic hepatitis B. J Infect Dis 2016;213:966-974. doi: 10.1093/ infdis/jiv547.

[40] Zhu H, Chen X. Research advances in molecular mechanism and treatment of metastasis and recurrence of primary liver cancer. Chin J Hepatobiliary Surg 2004;10:68-70. doi: 10.3760/cma.j.issn.1007-8118.2004.01.034

[41] Expert consensus on antiviral therapy to treat hepatitis $B / C$ virus-related hepatocellular carcinoma. Zhonghua Gan Zang Bing Za Zhi 2014;22: 321-326.

[42] Mittal D, Gubin MM, Schreiber RD, Smyth MJ. New insights into cancer immunoediting and its three component phases-elimination, equilibrium and escape. Curr Opin Immunol 2014;27:16-25. doi: 10.1016/j.coi.2014. 01.004.

[43] Schreiber RD, Old LJ, Smyth MJ. Cancer immunoediting: integrating immunity's roles in cancer suppression and promotion. Science 2011;331: 1565-1570. doi: 10.1126/science. 1203486 .

[44] Yu SJ, Kim YJ. Hepatitis B viral load affects prognosis of hepatocellular carcinoma. World J Gastroenterol 2014;20:12039-12044. doi: 10.3748/wjg. v20.i34.12039.

[45] Zhu SS, Dong Y, Xu ZQ, Wang LM, Chen DW, Gan Y, et al. A retrospective study on HBsAg clearance rate after antiviral therapy in children with $\mathrm{HBeAg}$ positive chronic hepatitis B aged 1-7 years. Zhonghua Gan Zang Bing Za Zhi 2016;24:738-743. doi: 10.3760/cma.j.issn.1007-3418.2016.10.005.

[46] Zhang HF. Antiviral therapy in children hepatitis B patients. Zhonghua Gan Zang Bing Za Zhi 2010;18:495-497. doi: 10.3760/cma.j.issn.1007-3418. 2010.07.006.

[47] Sarr C, Deng $H$, Snoeck E, Zhang $H$, Assy N, Lobzin $Y$, et al. Population pharmacokinetic analysis of peginterferon alfa-2a (40KD) supports use of BSA-category based dosing in children with chronic hepatitis B: PEG-BACTIVE pharmacokinetic substudy. Hepatology 2016;63:929A.

[48] Li MH, Xie R. Expert consensus on clinical management of adverse reactions in interferon- $\alpha$ therapy of chronic viral hepatitis. Chin J Exp Clin Infect Dis (Electronic Edition) 2014;1:108-113. 